\title{
Validation of a Rapid Visual Screening of Campylobacter jejuni in Chicken Using Antibody-Conjugated Fluorescent Dye-Doped Silica Nanoparticle Reporters
}

\author{
Wanwisa Poonlapdecha $\mathbb{D}^{1},{ }^{1}$ Yortyot Seetang-Nun $\left(\mathbb{D},{ }^{2}\right.$ Kooranee Tuitemwong $\mathbb{D}^{3}{ }^{3}$ \\ and Pravate Tuitemwong $\mathbb{D}^{1,2}$ \\ ${ }^{1}$ Department of Microbiology, Bioscience Program, Risk and Decision Assessment Lab., Faculty of Science, King Mongkut's University \\ of Technology Thonburi, Bangkok 10140, Thailand \\ ${ }^{2}$ Food Safety Center, Institute for Scientific and Technological Research and Services, King Mongkut's University of Technology \\ Thonburi, Bangkok 10140, Thailand \\ ${ }^{3}$ Department of Microbiology, Faculty of Science, Kasetsart University, Bangkok 10900, Thailand
}

Correspondence should be addressed to Kooranee Tuitemwong; fscikrt@ku.ac.th and Pravate Tuitemwong; ptt59@hotmail.com

Received 19 March 2018; Revised 17 May 2018; Accepted 20 May 2018; Published 14 August 2018

Academic Editor: Hassan Karimi-Maleh

Copyright $\odot 2018$ Wanwisa Poonlapdecha et al. This is an open access article distributed under the Creative Commons Attribution License, which permits unrestricted use, distribution, and reproduction in any medium, provided the original work is properly cited.

\begin{abstract}
The objective of this work was to validate the antibody-conjugated fluorescent dye-doped silica nanoparticle- (FDS-NP-) based assay for the rapid detection of Campylobacter jejuni in chicken samples using ISO16140:2003 single-laboratory validation guidelines. This assay reversed the paradigm of microbial testing. The noncultured FDS-NPs increased the fluorescent light signal of the test, not the cell numbers, and significantly reduced the detection time. Validation results showed that relative detection level (LOD) of the assay was $10^{3} \mathrm{cfu} / \mathrm{ml}$. The antibody-conjugated FDS-NPs were evaluated for the detection of $C$. jejuni in 140 chicken samples collected from slaughterhouses (50 carcass rinse water, 60 rectal swabs, and 30 viscera contents) against ISO 10272 reference method with duplex PCR confirmation. The relative accuracy (AC), relative specificity (SP), and relative sensitivity (SE) were $95.67 \%, 100 \%$, and $94.87 \%$, respectively. The inclusivity test of C. jejuni strains was $100 \%$ positive. The exclusivity test demonstrated no cross-reactivity with 32 strains of non-Campylobacter strains. The FDS-NP assay was very fast and specific, with time to result of $30 \mathrm{~min}$ compared with the $2-5$ days required by the reference method. The noncultured FDS-NPs demonstrated comparable performance to the cultured reference method to detect $C$. jejuni in poultry samples. It is applicable for effective screening of poultry product category.
\end{abstract}

\section{Introduction}

Campylobacter spp. from chicken has been considered the major cause of gastrointestinal campylobacteriosis [1]. Outbreaks of C. jejuni were reported worldwide with chicken meats identified as implicated foods $[2,3]$. In the United States, the number of patients with C. jejuni infection was as high as 1000 per 100,000 population. However, more than $80 \%$ of chickens are marketed without detectable Campylobacter [4]. In poultry processing plants, about $65 \%$ of Campylobacter positive flocks were reported in the central and northeastern regions of Thailand [5], and $26.6 \%$ were reportedly found in the central markets. During slaughter and processing, there is a chance of bacterial contamination to the finished products.

The detection and identification of the microorganisms are of great importance for poultry production to allow implementing proper and timely interventions that can ensure safety of the products. Traditional microbiological methods of detecting and enumerating bacteria usually require several days to yield reliable results. In many cases, the products have already been used by the consumers before the analyses are completed. Therefore, alternative rapid assays based on different microbiological methods are 


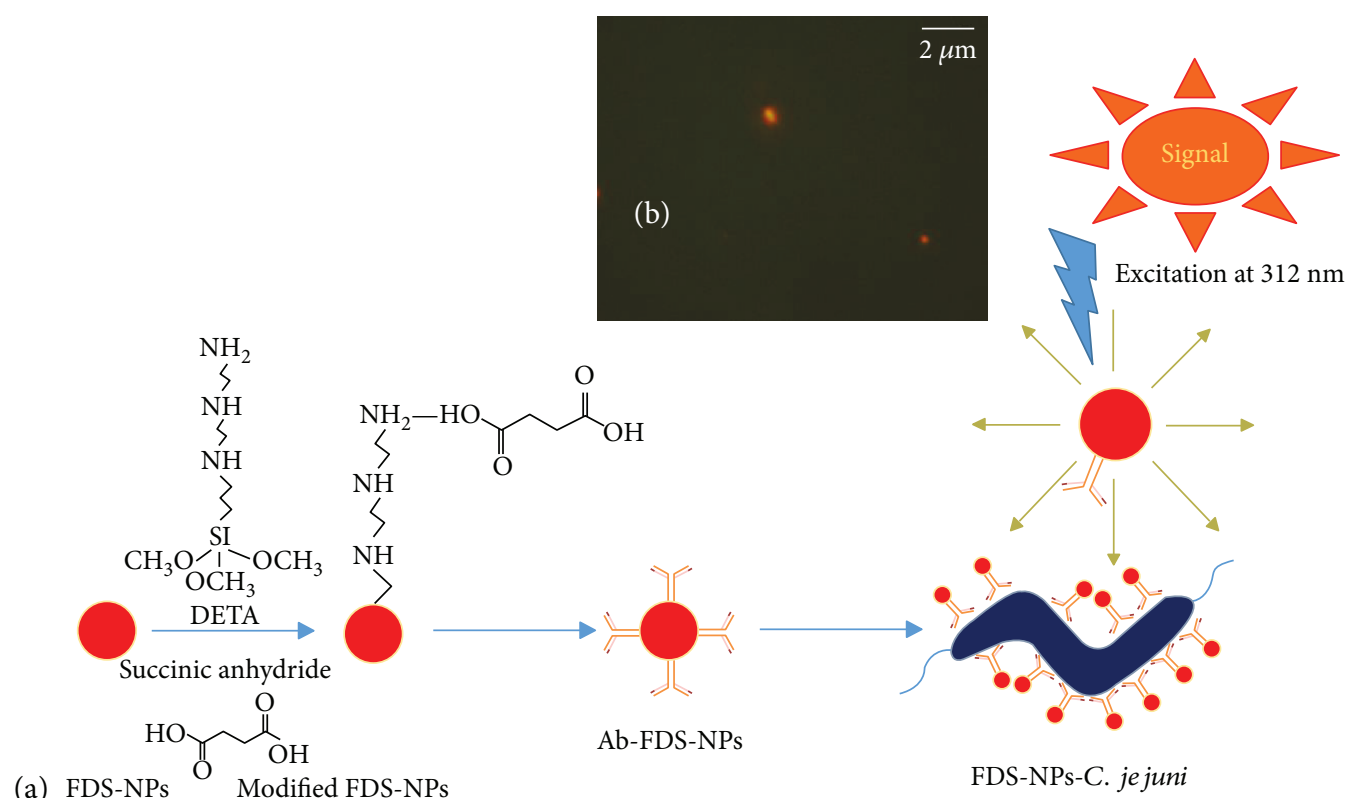

Figure 1: (a) Schematic illustration of the detection of $C$. jejuni using FDS-NPs as signal reporters. (b) Visualization of $C$. jejuni with FDS-NPs complex under fluorescent microscope. The bound C. jejuni showed extremely bright orange color with FDS-NPs at 1000x. Scale bar indicates $2 \mu \mathrm{m}$.

constantly developed [6]. The effective testing of bacteria requires methods of analysis that meet a number of challenging criteria. Time and sensitivity of analysis are the most important limitations related to the usefulness of microbiological testing. Bacterial detection methods have to be rapid and very sensitive since the presence of even a single pathogenic organism in foods may be an infectious dose [7]. Most rapid methods utilize principles of microbiological-, chemical-, biochemical-, immunological-, and molecular-based techniques, which may require cells, metabolites, or genetic materials of the target bacteria for detection. The methods that are nonculture-based method could further reduce time required for growth and production of microbial metabolites for detection.

The current development of nanotechnology has affected a variety of sciences including microbiology. The research findings have changed traditional methods into nanoscale that can be combined with different techniques to develop detection methods. Combining sol-gel and microemulsion techniques, Santra et al. [8] synthesized FDS-NPs, which encapsulated thousands of fluorescent dye molecules inside the nanoparticles. The silica nanoparticles gave high intensity of the fluorescent signal and high photostability due to dye molecules doped within silica matrix. They showed high solubility, low toxicity, and easy conjugation with various applications with several biomolecules, with or without surface modifications. The experiments on synthesis, characterization, and application of the FDS-NPs were reported. Hun and Zhang [9] used FDS-NPs for the determination of calcium in the blood serum. Zhao et al. [10] used FDS-NPs combined with flow cytometry for single bacterial cell quantification. A method suggesting the use of nanoparticles for the detection of Mycobacterium tuberculosis was also reported [11]. Extensive reviews on the applications of nanoparticles in rapid detections were carried out by Koedrith et al. [12, 13].

Our research group had developed silica and ferromagnetic nanoparticle-based detection for Vibrio cholerae in seafoods, Salmonella spp., E. coli O157:H7, and C. jejuni in poultry and products [14-18]. These methods showed potential applications in the routine use. Schematic illustration of the silica nanoparticle-based test method is shown in Figure 1. However, they require proper validation to demonstrate the performance compared with that of the reference methods. The antibody-conjugated dye-doped silica nanoparticle-based detection has potential to provide a rapid and accurate screening test results for slaughterhouses to manage the pathogen-free and infected flocks into the processing line. The practice will enable processors to avoid cross-contamination to processing equipment and eventually poultry meats.

Alternative microbiological test methods require proper validation as guided by ISO 16140:2003 [19], the general principles and the technical protocol for the validation of alternative methods in the field of microbiological analysis of food, animal feeding stuffs, and environmental and veterinary samples, or by AOAC validation methods, to ensure that accuracy, specificity, sensitivity, ruggedness, and consistency of the method are met before use in the industry.

Therefore, the objective of this work was to validate test kit based on fluorescent dye-doped antibody-conjugated silica nanoparticles (FDS-NPs) for the rapid detection of Campylobacter jejuni in chicken samples following the single-laboratory method validation procedure of ISO 16140:2003 standard. 
TABLE 1: List of $16 \mathrm{~S} R N A$ and hipO PCR primers for identification and confirmation of C. jejuni.

\begin{tabular}{lcccc}
\hline Target genes & Primer names & Sequences $\left(5^{\prime} \rightarrow 3^{\prime}\right)$ & Lengths $(\mathrm{bp})$ & References \\
\hline \multirow{2}{*}{$16 \mathrm{~S}$ RNA } & C412F & GGATGACACTTTTCGGAGC & 816 & {$[21]$} \\
& C1228R & CATTGTAGCACGTGTGTC & & {$[22]$} \\
\hline \multirow{2}{*}{ hipO } & CJF & ACTTCTTTATTGCTTGCTGC & 323 & {$[23]$} \\
& CJR & GCCACAACAAGTAAAGAAGC & & \\
\hline
\end{tabular}

Note: 16S RNA: 16S ribosomal RNA gene; hipO: hippuricase gene; F: forward orientation; R: reverse orientation; CJ: C. jejuni; and C1228, C412F: primers for Campylobacter.

\section{Materials and Methods}

2.1. Cultures and Preparation of Bacteria. C. jejuni (ATCC 33560 ), ranging from $10^{1}$ to $10^{7} \mathrm{cfu} / \mathrm{ml}$, was used to determine the limit of detection (LOD). Reference strains of $C$. jejuni (ATCC 33291, ATCC 33560, and ATCC 81176) and 47 in-house isolates of Campylobacter spp. from chicken samples were used for inclusivity testing. All Campylobacter strains were grown under microaerobic conditions $\left(5 \% \mathrm{O}_{2}\right.$, $10 \% \mathrm{CO}_{2}$, and $85 \% \mathrm{~N}_{2}$ ) on the modified charcoalcefoperazone-deoxycholate agar (mCCDA, Oxoid, UK) at $42^{\circ} \mathrm{C}$ for $48 \mathrm{~h}$. Other nontarget bacteria $\left(10^{3} \mathrm{cfu} / \mathrm{ml}\right)$, Bacillus megaterium, Citrobacter freundii, Escherichia coli, Klebsiella pneumoniae, Proteus vulgaris, Pseudomonas aeruginosa, Salmonella Typhimurium (DMST 562), Shigella flexneri, and Vibrio cholerae, and E. coli $(n=10)$ and Salmonella spp. $(n=13)$ in-house isolates from slaughterhouse samples were grown in Tryptone Soya Broth (TSB, Oxoid, UK) at $37^{\circ} \mathrm{C}$ overnight and used as exclusive strains. All test bacteria were collected and diluted with phosphate buffer saline (1x PBS, pH 7.4). The initial bacteria concentrations were determined using McFarland number 0.5 (Thermo Scientific, USA) and verified by mCCDA plating methods.

2.2. Collection and Preparation of Chicken Samples. All chicken samples: carcass rinse water $(n=50)$, rectal swabs $(n=60)$, and viscera contents $(n=30)$, were collected from slaughterhouses in Thailand. The collected samples were transported on ice to the laboratory within $2 \mathrm{~h}$ and processed immediately after arrival. In general, $1.0 \mathrm{ml}$ of carcass rinse water and rectal swabs and approximately $1.0 \mathrm{~g}$ in weight of viscera contents were prepared and 10-fold serially diluted with $0.85 \%$ of sodium chloride $(\mathrm{NaCl})$. Then, $0.1 \mathrm{ml}$ aliquots of the prepared samples with appropriate dilutions were taken and separately analyzed, according to the protocols as described below to determine the presence of $C$. jejuni in the samples.

2.3. Direct Culture with Duplex PCR Assay for Identification of C. jejuni. The standard method for culturing C. jejuni was ISO 10272:2006 [20]. The confirmation was modified to use duplex PCR for 16S RNA and hipO genes specific to $C$. jejuni to replace biochemical tests of hippuricase activity. Briefly, aliquots of $0.1 \mathrm{ml}$ samples were directly applied onto modified charcoal-cefoperazone-deoxycholate agar (mCCDA) plates, supplemented with cefoperazone $(32 \mathrm{mg} / \mathrm{l})$ and amphotericin B $(10 \mathrm{mg} / \mathrm{l})$, followed by incubation at $42^{\circ} \mathrm{C}$ for $48 \mathrm{~h}$ under microaerobic conditions.
Colonies with characteristics of greyish, moist, and metallic sheen were identified as thermophilic Campylobacter species. The suspected colonies were counted, and five colonies were selected for duplex PCR analysis for confirmation. To prepare the DNA template, the selected colonies were suspended in sterile water and boiled for $10 \mathrm{~min}$. The supernatants ( $5 \mu \mathrm{l}$ per assay) were collected and used as PCR templates.

For PCR amplification, the $16 \mathrm{~S} R N A$ and hipO primers were specifically designed for thermophilic Campylobacter and C. jejuni, respectively. The corresponding nucleotide sequences are shown in Table 1. The PCR mixtures contained $5 \mu \mathrm{l}$ of PCR master mix (Molecular Biology Tools, Taiwan), $1.5 \mu \mathrm{l}$ of each PCR primer $(10 \mu \mathrm{M})$, and sterile water to a final volume of $25 \mu \mathrm{l}$. Amplification reaction was conducted in $\mathrm{T} 100^{\mathrm{TM}}$ Thermal Cycler (Bio-Rad, USA) with the following conditions: $95^{\circ} \mathrm{C}$ for $5 \mathrm{~min}$ for initial denaturation, followed by $30 \mathrm{cycles}$ of $95^{\circ} \mathrm{C}$ for $30 \mathrm{sec}, 59^{\circ} \mathrm{C}$ for $30 \mathrm{sec}$, and $72^{\circ} \mathrm{C}$ for $30 \mathrm{sec}$, and final extension at $72^{\circ} \mathrm{C}$ for $5 \mathrm{~min}$. The PCR products were analyzed by agarose gel electrophoresis. The sample containing specific DNA bands of approximately 816 and 323-bp in length corresponding to 16S RNA and hipO genes, respectively, was determined as a $C$. jejuni, whereas the presence of only $16 \mathrm{~S} R N A$ fragments was identified as Campylobacter species. No amplification products were considered as negative results.

2.4. Synthesis of FDS-NPs and Surface Modifications. Synthesis of FDS-NPs and surface modifications were carried out as previously described $[14,15,17,18]$. Briefly, mixtures of cyclohexane $(75 \mathrm{ml})$, Triton $\mathrm{X}-100(17.7 \mathrm{ml})$, and $n$-hexanol $(18 \mathrm{ml})$ as oil, surfactant, and cosurfactant phases, respectively, were mixed with $4.8 \mathrm{ml}$ aliquots of Rubpy dye solution (20 $\mathrm{mM}$ in deionized water). Then, $1 \mathrm{ml}$ of tetraethyl orthosilicate (TEOS) as silica precursors and $0.6 \mathrm{ml}$ of ammonium hydroxide as initiators for polymerization reaction, respectively, were added in and mixed by stirring for $24 \mathrm{~h}$. Afterwards, the FDS-NPs were obtained by precipitation with acetone. After centrifugation, they were washed with ethanol and deionized water several times to remove the excess solvents and unabsorbed dye, dried at $100^{\circ} \mathrm{C}$ for $48 \mathrm{~h}$, and kept in the dark until further used.

For surface modifications, the FDS-NPs (32 mg) were added in $1 \mathrm{mM}$ of acetic acid containing $10 \%$ of trimethoxysilylpropyl diethylenetriamine (DETA) and stirred for $30 \mathrm{~min}$ to produce the amine functional group. Then, the carboxyl functional group was generated by adding $20 \mathrm{ml}$ of $\mathrm{N}, \mathrm{N}$-dimethylformamide containing $10 \%$ of 
succinic anhydride and stirred for $6 \mathrm{~h}$ under nitrogen gas. Transmission electron microscopy (TEM) from Hitachi High Tech (model 7700, Japan) and Fourier-transform (FT) Raman spectroscopy from Bruker (model Vertex70 + RamII, Singapore) were used to determine the shape and size of FDS-NPs and the functional groups on the nanoparticle's surfaces, respectively. All chemicals and reagents used were from Sigma-Aldrich (USA).

2.5. Bioconjugation of Specific Antibody for C. jejuni. Following chemical modifications, the surfaces of FDS-NPs were further cross-linked with 1-ethyl-3-(3-dimethyl aminopropyl) carbodiimide hydrochloride (EDC) and N-hydroxy succinimide (NHS) system, followed by glutaraldehyde cross-linking and bioconjugation with specific monoclonal antibody $(0.1 \mathrm{mg} / \mathrm{ml}$, ab33023; Abcam, UK) towards $C$. jejuni. The particles were blocked with bovine serum albumin (BSA, 1\%) in Tris- $\mathrm{HCl}$ solution (40 mM, pH 8.0), washed with $\mathrm{PBS}(1 \mathrm{x}, \mathrm{pH} 7.4)$, and then stored at $4^{\circ} \mathrm{C}$ until further use.

2.6. Visual Detection of C. jejuni Using Antibody-Conjugated FDS-NPs as Reporters. Aliquots of $0.1 \mathrm{ml}$ bacterial culture were incubated with $20 \mu \mathrm{l}$ of antibody-conjugated FDS-NPs at room temperature $\left(25^{\circ} \mathrm{C}\right)$ for $30 \mathrm{~min}$ with gentle agitation. The bacteria cell/FDS-NP complexes (approximately $20 \mu \mathrm{l}$ ) were dropped onto a slide and covered with clover glass. The presence of $C$. jejuni in each sample was visually observed under a fluorescence microscope (Carl Zeiss, Primo Star iLED, USA) with excitation wavelength of $312 \mathrm{~nm}$. The images were captured with a digital camera (Canon, EOS $700 \mathrm{D}$, Thailand). PBS buffer (1x) was used as a negative control throughout the experiments. The presence of large fluorescent orange dots with movement of live bacterial cells was denoted as a positive result, whereas the samples containing only very small fluorescent orange dots with Brownian movement of the nanoparticles indicated a negative result.

2.7. Validation of the Assay Using ISO 16140:2003 as Guidelines. According to ISO 16140:2003 [19], there were 3 tests to perform: relative detection level (LOD), selectivity (inclusivity/exclusivity), and comparative study.

2.7.1. Relative Level of Detection. The LOD was tested with pure culture of C. jejuni ATCC 33560 at different concentrations with six independent replications.

2.7.2. Selectivity Test. The inclusivity tests were conducted with pure cultures of 50 strains including C. jejuni ATCC 33291, ATCC 33560, and ATCC 81176 and 47 Campylobacter isolates collected from poultry slaughterhouses and confirmed and enlisted in our laboratory. On the other hand, the exclusivity tests were against nontarget organisms using 32 strains of Bacillus megaterium, Citrobacter freundii, Escherichia coli, Klebsiella pneumonia, Proteus vulgaris, Pseudomonas aeruginosa, Salmonella Typhimurium (DMST 562), Shigella flexneri, and Vibrio cholerae, including inhouse isolates of $10 \mathrm{E}$. coli, and 13 Salmonella strains.
2.7.3. Comparative Study. According to EN ISO 16140 standard, a minimum of 60 products from 3 product types under the poultry category must be analyzed with approximately $50 \%$ positive and 50\% negative products. The reference method was modified ISO 10272-1:2017 "Microbiology of the Food Chain-Horizontal Method for Detection and Enumeration of Campylobacter spp.--Part 1: Detection Method" [20]. Samples were prepared and divided to test in parallel with FDS-NPs and the reference methods. Suspected colonies on mCCDA were confirmed by duplex PCR. Results from FDS-NPs were used for calculation of relative accuracy (AC), relative specificity (SP), and relative sensitivity (SE) in comparison with results of the reference method. The values were calculated for each poultry sample type and in pool results. Positive predictive value (PPV) and negative predictive values (NPV), as well as Cohen's kappa index of concordance $(k)$, were calculated to determine the efficacy of the assay for detection of $C$. jejuni against the reference method. The formula for calculations is as follows:

$$
\begin{aligned}
& \mathrm{AC}=\left[\frac{\mathrm{PA}+\mathrm{NA}}{N}\right] \times 100, \\
& \mathrm{SP}=\left[\frac{\mathrm{NA}}{\mathrm{PD}+\mathrm{NA}}\right] \times 100, \\
& \mathrm{SE}=\left[\frac{\mathrm{PA}}{\mathrm{PA}+\mathrm{ND}}\right] \times 100, \\
& \mathrm{PPV}=\left[\frac{\mathrm{PA}}{\mathrm{PA}+\mathrm{PD}}\right] \times 100, \\
& \mathrm{NPV}=\left[\frac{\mathrm{NA}}{\mathrm{NA}+\mathrm{ND}}\right] \times 100, \\
& 2 \times[(\mathrm{PA} \times \mathrm{NA})-(\mathrm{PD} \times \mathrm{ND})] \\
& k=\frac{\mathrm{PA}+\mathrm{PD}) \times(\mathrm{PD}+\mathrm{NA})]+(\mathrm{PA}+\mathrm{ND}) \times(\mathrm{NA}+\mathrm{ND})}{}
\end{aligned}
$$

where PA is positive accordance, $\mathrm{PD}$ is positive deviations, NA is negative accordance, ND is negative deviations, and $N$ is number of analyzed samples, respectively [19].

\section{Results}

3.1. Principle ofC.jejuni Detection Using Antibody-Conjugated FDS-NPs. The principle of this method was to use FDSNPs to attach on target cell surface. The loose particles were washed out, and the remaining aliquot was observed under fluorescent microscope for rapid detection of target cells of Campylobacter. The attempts were to increase light signals to identify the target cells under a fluorescent microscope, not to increase cell numbers that required much longer detection time. Results could be obtained in $30 \mathrm{~min}$.

3.2. Synthesis and Characterization of FDS-NPs. FDS-NPs were prepared using water-in-oil microemulsion-based techniques. The FDS-NPs had spherical shape and sizes of approximately $50 \mathrm{~nm}$ in diameter, as revealed by TEM image (Figure 2). 


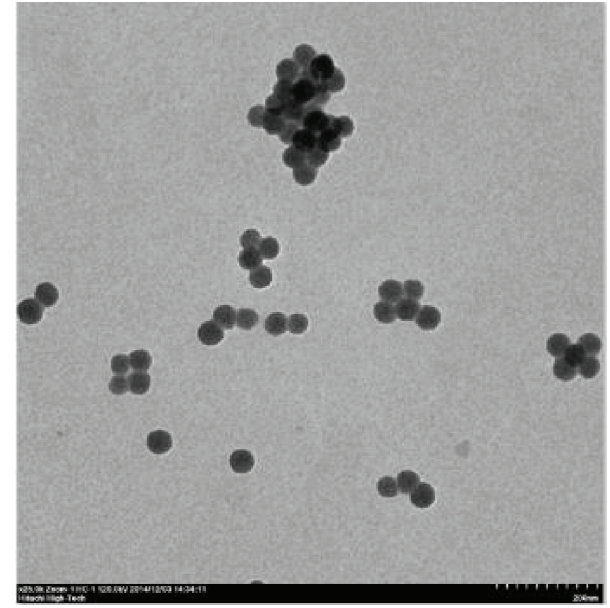

FIgURe 2: A TEM image of FDS-NPs. The synthesized FDS-NPs were spherical with average sizes of approximately $50 \mathrm{~nm}$. Scale bar indicates $200 \mathrm{~nm}$.

3.3. Surface Modification of FDS-NPs for Antibody Attachment. The surfaces of FDS-NPs were successfully modified with amine and carboxyl groups. The modification allowed the particles to attach to glutaraldehyde cross-link that could connect to monoclonal antibodies against Campylobacter jejuni. The presence of the functional groups on the nanoparticle surface was confirmed with FT-Raman analysis. Figure 3 demonstrated amine group N-H stretching at wave number $3216 \mathrm{~cm}^{-1}$ and carboxyl group $(\mathrm{C}=\mathrm{O})$ at $1639 \mathrm{~cm}^{-1}$.

3.4. Validation of Antibody-Conjugated FDS-NP Assay Using ISO 16140:2003 Guidelines. FDS-NPs were validated against standard mCCDA plating method (ISO 10272:2006) with multiplex PCR confirmation following ISO 16140:2003. Relative detection level, selectivity (inclusivity/exclusivity tests), and comparative studies for relative accuracy, specificity, and sensitivity were tested.

3.4.1. Relative Level of Detection (LOD). Figure 4 demonstrated the relative level of detection (LOD) of FDS-NP test. Images of cells under fluorescent microscope indicated that the FDS-NPs could detect Campylobacter at $10^{3} \mathrm{cfu} / \mathrm{ml}$. No orange spot was observed at $10^{2} \mathrm{cfu} / \mathrm{ml}$ level.

Please see Supplementary Materials (available here) for information on Section 3.4.1.

3.4.2. Selectivity Test: Inclusivity and Exclusivity. The alternative FDS-NPs method was tested against 50 strains of $C$. jejuni for inclusivity. Results showed that the FDS-NPs could detect $100 \%$ of all inclusive strains. FDS-NPs also gave $100 \%$ negative results for all 32 exclusive strains tested. No crossreaction was observed among the tested strains.

Please see Supplementary Materials for information on Section 3.4.2.

3.4.3. Comparative Study: Relative Accuracy (AC), Relative Specificity (SP), Relative Sensitivity (SE), Positive Predictive Value (PPV), and Negative Predictive Value (NPV). The tests provided results for calculation of relative AC, SP, SE, PPV, and NPV values. The Samples of 3 types from poultry category, 50 carcass rinse samples, 60 rectal swabs, and 30 viscera contents, were analyzed in parallel with reference and alternative methods. Sample types represented low, medium, and high naturally contaminated levels. The values were calculated by comparing with results from the reference method, mCCDA plating with duplex PCR confirmation (Figure 5). Calculated results were shown in Table 2.

Figure 5 demonstrated gel patterns of samples containing specific DNA bands of approximately 816 and $323 \mathrm{bp}$ in length of corresponding $16 \mathrm{~S}$ RNA and hipO genes. The lanes with two bands were determined as positive results of $C$. jejuni, whereas the presence of only 16S RNA fragments represented Campylobacter species. Lane C, control, was C. jejuni ATCC 33291, and lanes 1-9 were C. jejuni isolated from viscera contents. Amplified products that failed to show these two bands were considered as negative result (lane $\mathrm{N}$ ).

FDS-NPs exhibited high efficiency for samples with medium to high contamination levels (Table 2). The values of $\mathrm{AC}, \mathrm{SP}$, and SE (\%) of the FDS-NPs, for carcass rinse samples, were also high at 92.00, 100, and 86.67, respectively. The values for rectal swab samples were 98.33 , 100 , and 98.3. The values of viscera contents were also high at $96.67,100$, and 96.42 .

This observation was supported by high values of PPV at $100 \%$ for all sample types tested. PPV values were calculated from $P P V=$ true positive results $(\mathrm{PA}) /($ true posive $(\mathrm{PA})+\mathrm{fa}$ lse positive $(\mathrm{PD})) \times 100$. The alternative FDS-NPs could detect $C$. jejuni target in all poultry samples and give no positive deviation.

There were 4 negative deviations with carcass samples, 1 with rectal swab and 1 with viscera content samples. The deviation affected the SE values of the test. The NPV values that indicated false negative outcomes were calculated from $N P V=$ true negative results $(\mathrm{NA}) /$ true nega tive $(\mathrm{NA})+$ false negative $(\mathrm{ND}) \times 100$. The values of $\mathrm{NPV}$ were $83.33 \%$ for carcass rinse samples but were $50 \%$ and $66.67 \%$ for rectal swab and viscera contents, respectively. The low values could be caused by low numbers of negative samples (NA) of rectal swabs and viscera contents. A few deviated results, $\mathrm{ND}=1$ in this case, but at low negative samples $(\mathrm{NA}=2)$, greatly affected the NPV values.

The comparison was made with all sample types, 140 samples, of the poultry category, and results were tabulated in Table 3. There were $111 \mathrm{PA}$ or TP without any PD or FP. However, 6 NDs were observed. The number of NA or $\mathrm{TN}$ was 23.

Table 4 demonstrated pool results of 140 samples for calculations of AC, SP, SE, PPV, NPV, and $k$ values. It was found that the AC, SP, and SE values of the FDS-NP alternative method were high, with values of $95.67 \%, 100 \%$, and $94.87 \%$, respectively. PPV and NPV values were at $100 \%$ for positive and $79.31 \%$ for negative predictions. The PPV value of $100 \%$ indicated no false positive of this test. The NPV value of $79.31 \%$ indicated that false negative could be found in this test compared with results from the reference method. The combined results showed very high correlation of the alternative and reference methods with the Cohen kappa index $(k)$ of 0.86 . 


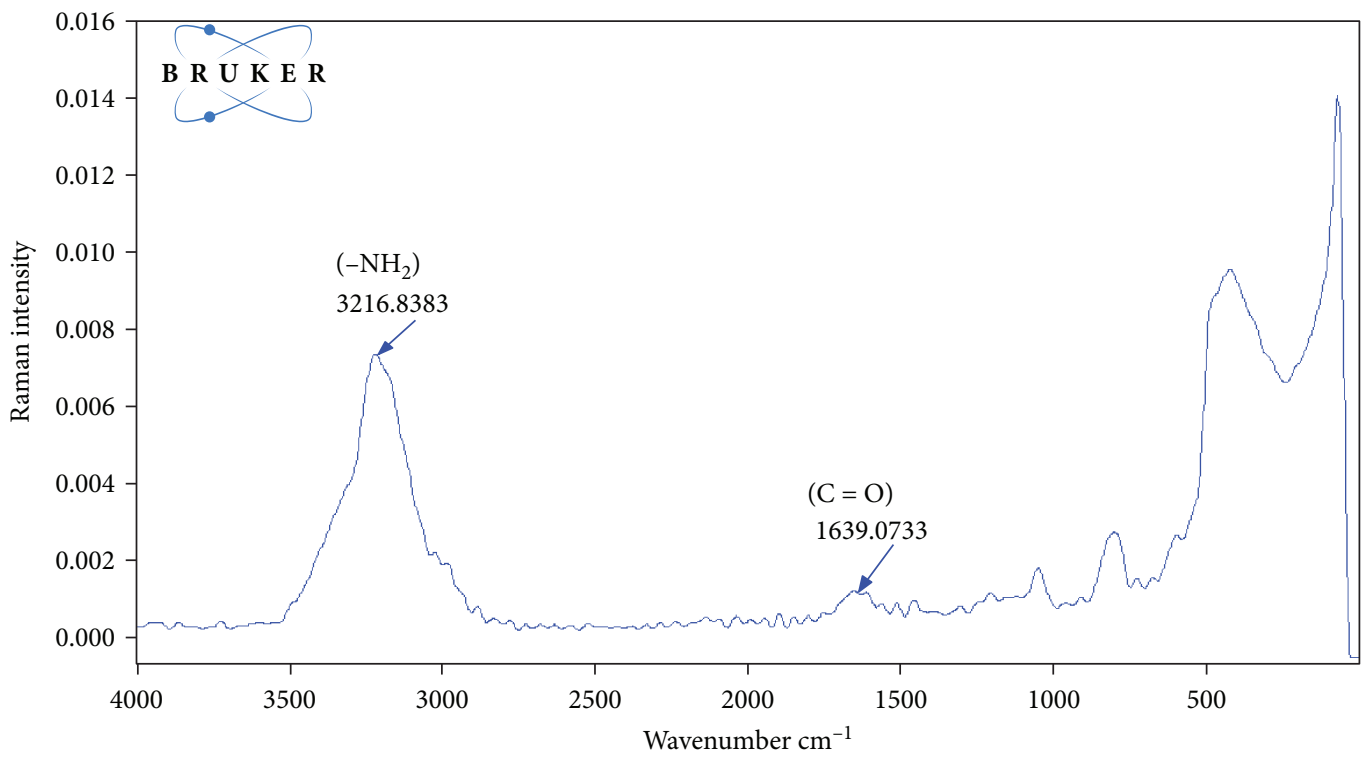

FIGURE 3: FT-Raman spectra of FDS-NPs with amine and carboxyl surface modifications. The spectra at 3216 and $1639 \mathrm{~cm}^{-1}$ indicate the existence of amine and carboxyl functional groups on the particles.
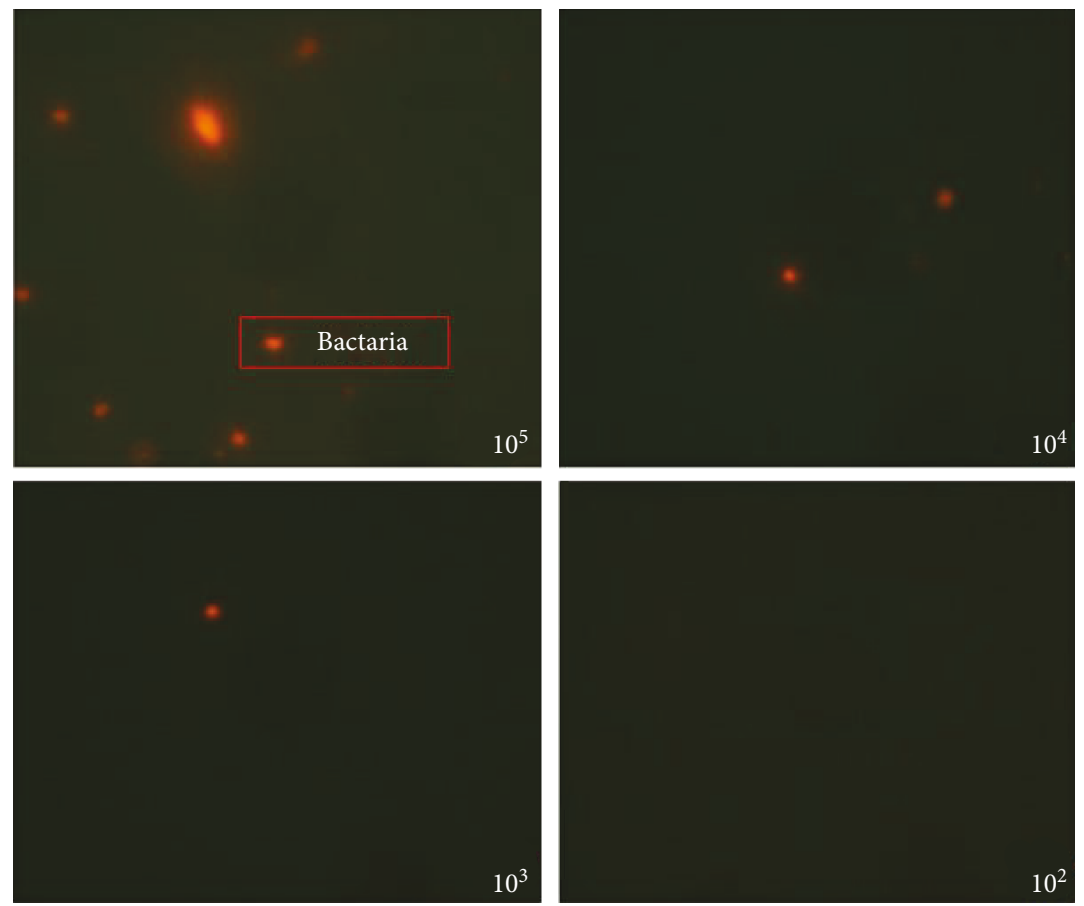

FigURE 4: Relative LOD of serially diluted pure culture of $C$. jejuni (ATCC 33560) $(n=6)$. The small but uniform bright spots were considered bacterial cells. Positive $\left(10^{3}\right.$ to $\left.10^{5} \mathrm{cfu} / \mathrm{ml}\right)$ and negative $\left(10^{2} \mathrm{cfu} / \mathrm{ml}\right)$ results under fluorescent microscope were demonstrated. The relative LOD of the proposed assay was $10^{3} \mathrm{cfu} / \mathrm{ml}$.

\section{Discussion}

\subsection{Fluorescent Dye-Doped Silica Nanoparticle Characteristics}

4.1.1. Principles of FDS-NP Method. FDS-NP assay is a noncultured method. The principles for detection of $C$. jejuni used antibody-conjugated FDS-NPs as signal reporters and relied on the increase of fluorescent signal rather than the increase of target cells. Fluorescent dye-doped molecules inside the FDS-NP particles and the number of particles covering the target cells produced significant light intensity for observation under the fluorescent microscope. The specific binding to target $C$. jejuni cells was aided by specific monoclonal antibody immobilized on the surfaces of nanoparticles. The excitation wavelength of $312 \mathrm{~nm}$ enables the 


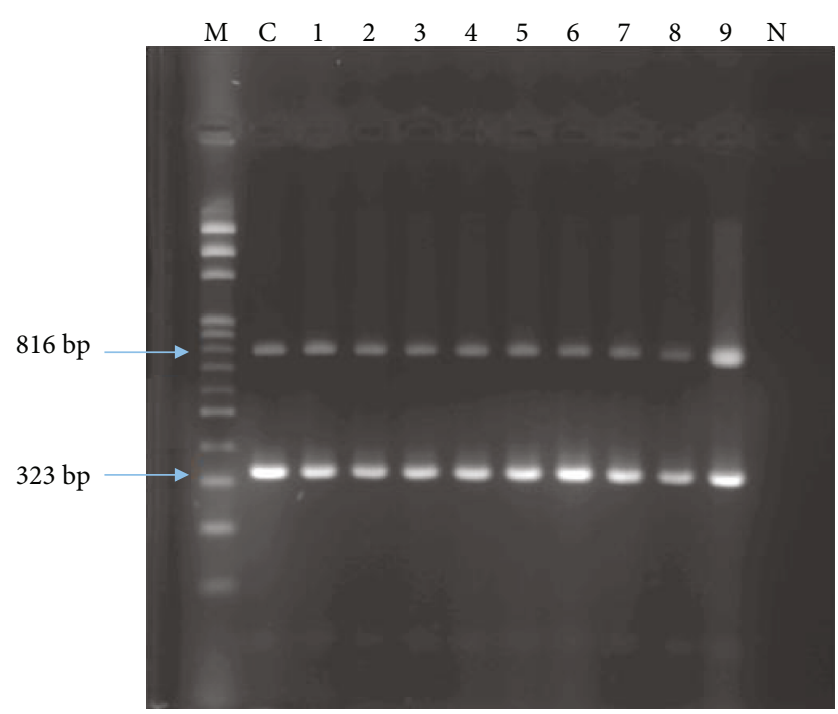

FIgUre 5: Gel patterns of PCR products for confirmation of $C$. jejuni contamination by duplex PCR assay. Positive result showed two bands of PCR amplicons specific for 16S RNA (816bp) and hipO (323 bp) genes. Lane M: molecular weight marker; lane $C$ : $C$. jejuni (ATCC 33291) as a positive control; lanes 1-9: selected $C$. jejuni colonies from the mCCDA plates of viscera contents; and lane $\mathrm{N}$ : sterile water was used as a negative control.

fluorescent dyes in the nanoparticles to emit wavelengths of 590-600 nm. C. jejuni in complex with antibody-conjugated FDS-NPs showed extremely bright orange with rounded surface and moved randomly that could be observed easily under fluorescent microscope. In this study, a positive sample can be discriminated from a negative sample through brightness of the fluorescent signals. The positive samples had much brighter fluorescent light compared with the small and dispersed orange dots of the negative samples. The complex could be discriminated clearly from the irregular-shaped aggregates (if any).

4.1.2. Characteristics of FDS-NPs. The size of FDS-NPs of approximately $30-60 \mathrm{~nm}$ was consistent with that previously reported $[14,15,17,18]$. Thepwiwatjit et al. [14] reported the FDS-NPs with relatively narrow size of $29-43 \mathrm{~nm}$. The size distribution usually depended on synthesis techniques, equipment, time, maximum speed, size of magnetic stirrer, and container. After synthesis, the individual particle could be separated from big aggregated particles using centrifugation at low speed.

The surfaces of FDS-NPs were modified with amine and carboxyl groups. DETA and succinic anhydride were used to modify amine and carboxyl groups on the particle surface. The EDC/NHS coupling was treated on the particle surface for enhancing stability of the carboxyl group. FT-Raman spectra showed peaks at wave numbers 3400 to $3280 \mathrm{~cm}^{-1}$ that represent $-\mathrm{NH}_{2}$ asymmetric and symmetric stretching vibration. The data supported the existence of amino group from being modified by DETA. The band of 1630$1600 \mathrm{~cm}^{-1}$ indicated the $\mathrm{C}=\mathrm{O}$ symmetric stretch [24] due to the addition of the carboxyl group on the particle surface.
This finding was corresponding well with that of Gunasekaran et al. [25], Tansub et al. [17], and Tuitemwong et al. [18] who suggested that wave numbers $3500-3220 \mathrm{~cm}^{-1}$ indicated amine group N-H stretching and $1850-1550 \mathrm{~cm}^{-1}$ for carboxyl group $\mathrm{C}=\mathrm{O}$ on the FDS-NP surfaces.

4.2. Validation of FDS-NP Assay Using ISO 16140:2003 Guidelines. Method validation is designed to confirm that an analytical procedure for a specific test is reliable, reproducible, and suitable for its intended application. These analytical methods need to be validated prior to the implementation in routine. It is especially true for this novel nanotechnology platform, where paradigm is changed from increasing target cell numbers to increasing signal of the target cells that were captured by antibody-conjugated FDS-NPs. In this single-laboratory validation, there are three tests to follow: relative detection level, selectivity (inclusivity/exclusivity tests), and comparison study, to demonstrate relative accuracy (AC), relative specificity (SP), and relative sensitivity (SE) against the reference method.

4.2.1. Relative Detection Level (LOD). The objective of relative detection level was to determine the level of contamination to obtain $50 \%$ of positive results. To determine the LOD of the proposed assay, the FDS-NPs and reference methods were used to test various concentrations of the target $C$. jejuni ATCC 33560 ranging from $10^{1}$ to $10^{7} \mathrm{cfu} / \mathrm{ml}(n=6)$. It was found that the level of detection was $10^{3} \mathrm{cfu} / \mathrm{ml}$. Results showed that approximately $10^{3} \mathrm{cfu} / \mathrm{ml}$ of $C$. jejuni without enrichment gave positive signal as images shown in Figure 4. This assay was based on immune detection using specific antibody to detect the $C$. jejuni, the same principle as enzyme-linked immunosorbent assay (ELISA). Hochel et al. [26] applied the indirect competitive ELISA to determine Campylobacter spp. in foods using chemiluminescent substrate to give signal; they reported relative LOD in the range $10^{4}-10^{6} \mathrm{cfu} / \mathrm{ml}$. Sails et al. [27] developed a PCR ELISA assay to detect C. jejuni and C. coli in water and reported the LOD with enrichment process at cells lower than $10^{3} \mathrm{cfu} / \mathrm{ml}$. The FDS-NPs showed the favorable LOD compared to both methods. The lower LOD level could be achieved by applying short-time enrichment $(2-4 \mathrm{~h})$ before the test.

4.2.2. Selectivity: Inclusivity and Exclusivity. The FDS-NPs with monoclonal antibody showed high selectivity to $C$. jejuni. The selectivity was $100 \%$ positive to all C. jejuni targets and $100 \%$ negative to non-C. jejuni organisms. No crossreactivity was found in the tests of non-Campylobacter strain (exclusivity). The monoclonal antibody presented good specificity against $C$. jejuni with the presence of components such as fecal, feed, and lipid that might interfere to the FDS-NP attachment to target cells. The selectivity relied on specific binding of monoclonal antibodies with target $C$. jejuni owing to its 15 amino acids that were specific with the target organism [28].

4.2.3. Comparative Study. FDS-NPs showed high values of AC, SP, and SE to different levels of contaminations in carcass rinse, rectal swab, and viscera content samples. No false positive was observed. However, there were false negatives 
TABLE 2: Calculations of AC, SP, SE, PPV, and NPV values of the proposed assay for detection of C. jejuni in various analysed samples against the direct culture with duplex PCR assay as a reference method.

\begin{tabular}{lcccccccccccc}
\hline Analyzed samples & PA & PD & ND & NA & $N+(\mathrm{PA}+\mathrm{ND})$ & $N-(\mathrm{NA}+\mathrm{PD})$ & Total & AC $(\%)$ & SP $(\%)$ & SE $(\%)$ & PPV (\%) & NPV $(\%)$ \\
\hline Carcass rinses & 26 & 0 & 4 & 20 & 30 & 20 & 50 & 92.00 & 100 & 86.67 & 100 & 83.33 \\
Rectal swabs & 58 & 0 & 1 & 1 & 59 & 1 & 60 & 98.33 & 100 & 98.30 & 100 & 50.00 \\
Viscera contents & 27 & 0 & 1 & 2 & 28 & 2 & 30 & 96.67 & 100 & 96.42 & 100 & 66.67 \\
\hline
\end{tabular}

Note: PA: positive accordance; PD: positive deviations; NA: negative accordance; ND: negative deviations; $N$ : number of analyzed samples; $N+$ : total of positive samples compared with a reference method; $N$-: total of negative samples compared with a reference method; AC: relative accuracy; SP: relative specificity; SE: relative sensitivity; PPV: positive predictive value; and NPV: negative predictive value.

TABLE 3: Comparison of the proposed FDS-NPs assay for detection of $C$. jejuni in all samples $(n=140)$ against the direct culture on mCCDA with duplex PCR assay as a reference method. TP: true positive; FP: false positive; TN: true negative; FN: false negative.

\begin{tabular}{|c|c|c|c|}
\hline & & \multicolumn{2}{|c|}{$\begin{array}{c}\text { Reference method } \\
\text { Direct culture on mCCDA/PCR assay }\end{array}$} \\
\hline & & Positive $(+)$ & Negative (-) \\
\hline \multirow{3}{*}{ Antibody-conjugated FDS-NP assay } & Positive $(+)$ & TP 111 & FP 0 \\
\hline & Negative (-) & FN 6 & TN 23 \\
\hline & Total & 117 & 23 \\
\hline
\end{tabular}

TABle 4: The values of AC, SP, SE, PPV, NPV, and kappa coefficient of the FDS-NP assay for detection of $C$. jejuni in all samples $(n=140)$ against the reference method.

\begin{tabular}{|c|c|c|c|c|c|c|c|c|c|c|c|c|c|}
\hline Target bacterium & $\mathrm{PA}$ & $\mathrm{PD}$ & NA & ND & $N+(\mathrm{PA}+\mathrm{ND})$ & $N-(\mathrm{NA}+\mathrm{PD})$ & Total & $\mathrm{AC}(\%)$ & SP (\%) & SE (\%) & PPV (\%) & NPV (\%) & $k$ \\
\hline C. jejuni & 111 & 0 & 23 & 6 & 117 & 23 & 140 & 95.67 & 100 & 94.87 & 100 & 79.31 & $\overline{0.86}$ \\
\hline
\end{tabular}

with rectal swab and viscera samples that could be resulting from the interference of sample matrix on attachment of the particles on cell surface. Target cells at concentrations less than $10^{3} \mathrm{cfu} / \mathrm{ml}$ (LOD) were not detected by this method and produced not detected results (false negative).

The values of PPV and NPV demonstrated proportion of true positive and true negative results of the FDS-NP assay. High values of both numbers demonstrated high percentages of true positive and negative proportions. PPV value was calculated as the number of true positive over true positive combined with false positive results. The value of $100 \%$ indicated no false positive of this test.

Carcass rinse samples had high NPV values of $83.33 \%$ indicating low rate of false negative results. The NPV value of both rectal swabs and viscera contents was relatively low as $50 \%$ and $66.67 \%$, respectively. However, both sample types (rectal swabs and viscera contents) had only one discrepancy each, and carcass washing samples had 4 discrepancies. This false negative observation may be due to the low number of target cells, $10^{3}$ cells $/ g$. The results of mCCDA plate count with PCR assay gave positive for cells less than $10^{3} \mathrm{cfu} / \mathrm{g}$, but FDS-NPs displayed negative results. However, the low NPV values could be explained that it was because of too small numbers of negative samples (NA $=1$ and 2$)$ in this test. One discrepancy from 1 NA produced NPV of $50 \%$. A low number of negative samples could introduce bias in the calculations. It was difficult to find negative samples from naturally contaminated cloacal swabs and viscera content samples.
With the pooled data, $n=140$, the performance indexes, AC, SP, and SE, were high at $95.67 \%, 100 \%$, and $94.87 \%$, respectively (Table 4). The values of PPV and NPV were $100 \%$ and $79.31 \%$, respectively. The PPV values indicated good positive agreement, without positive deviation, of the two methods.

The Cohen kappa values were defined by Cohen [29] and Landis and Koch [30] as values of $\leq 0.20$ indicated poor agreement, between 0.21 and 0.40 fair agreement, between 0.41 and 0.60 moderate agreement, between 0.61 and 0.80 good agreement, and $\geq 0.81$ very good agreement. In this case, the Cohen kappa value of the two methods was 0.86 indicating very good agreement between the two methods.

Compared to other findings, the $48 \mathrm{~h}$ real-time PCR for Campylobacter spp. had AC, SP, and SE for fruit and vegetable products of $98.33 \%, 96.77 \%$, and $100 \%$, respectively. The values for dairy products were lower to about $93.3 \%, 88.24 \%$, and $100 \%$ [31]. The use of PCR combined with ELISA for Campylobacter detection compared with culture method gave a Cohen kappa value of 0.83 [32]. The FDS-NPs were able to give results equivalent to the more complicated method but with much less detection time and equipment. Lund et al. [33] used real-time PCR to determine Campylobacter spp. in chicken feces. The results showed relative LOD of $100-150 \mathrm{cfu} / \mathrm{ml}$ but the sample preparation and instrument were more complicated and time-consuming. The FDS-NPs were proved to be effective and rapid with almost real-time results for the rapid screening of C. jejuni 
and could be used in routine works with farm, chicken on truck, or poultry sample category.

\section{Conclusion}

The noncultured FDS-NPs with monoclonal antibody were successfully constructed with good consistency. Functional groups, amide and carboxyl, were attached onto the particle surface. Glutaraldehyde cross-linker could capture the functional group and allow antibodies to attach to the other end. That allowed FDS-NPs to readily bind on $C$. jejuni cell surface. The captured cells were extremely bright orange with rounded surface and movable under microscope. They could be discriminated clearly from the irregular shape aggregates.

Single-laboratory method validation of FDS-NPs against standard mCCDA plating with duplex PCR confirmation, following ISO16140:2003 guidelines, indicated that the FDS-MPs had a limit of detection level (LOD) of $10^{3} \mathrm{cfu} / \mathrm{ml}$. The method offered good specificity as all strains of Campylobacter jejuni were detected (inclusivity), and no cross-reactions were observed among the non-C. jejuni and other microflora tested (exclusivity). This performance was determined by analyzing 140 naturally contaminated samples from 3 types of poultry product category. The pooled sample relative accuracy (AC), specificity (SP), and sensitivity (SE) were high at $95.67 \%, 100 \%$, and $94.87 \%$, respectively. A very good agreement between the FDS-NPs and reference method was observed with Cohen kappa value of 0.86 . It was evident that noncultured FDS-NP method was very specific with much shorter time, $30 \mathrm{~min}$, compared to 2-5 days of the cultured reference method. The performance of FDSNP method was equivalent to that of the reference method.

\section{Data Availability}

The limit of detection section and inclusivity and exclusivity testing data used to support the findings of this study are included within the supplementary information file.

\section{Disclosure}

Yortyot Seetang-Nun's present address is Center of Excellence on Agricultural Biotechnology (AG-BIO/PERDOCHE), Bangkok 10900, Thailand.

\section{Conflicts of Interest}

The authors declare that there is no conflict of interest regarding the publication of this paper.

\section{Acknowledgments}

This work was supported by funding from The Royal Golden Jubilee Ph.D. Program (RGJ) under the Thailand Research Fund (TRF) (Grant no. PHD/0024/2555).

\section{Supplementary Materials}

Relative LOD: the FDS-NPs test kit $(n=6)$. Table 5: LOD of the antibody-conjugated FDS-NP assay. Supplementary Materials. Inclusive and exclusive testing. Table 6: testing of inclusive strain using antibody-conjugated FDS-NP assay (50 strains of C. jejuni). Table 7: testing of exclusive strain using antibody-conjugated FDS-NP assay (32 strains). (Supplementary Materials)

\section{References}

[1] J. Silva, D. Leite, M. Fernandes, C. Mena, P. A. Gibbs, and P. Teixeira, "Campylobacter spp. as a foodborne pathogen: a review," Frontiers in Microbiology, vol. 2, p. 200, 2011.

[2] M. Mäesaar, K. Praakle, K. Meremäe et al., "Prevalence and counts of Campylobacter spp. in poultry meat at retail level in Estonia," Food Control, vol. 44, pp. 72-77, 2014.

[3] S. M. Pires, H. Vigre, P. Makela, and T. Hald, "Using outbreak data for source attribution of human salmonellosis and Campylobacteriosis in Europe," Foodborne Pathogens and Disease, vol. 7, no. 11, pp. 1351-1361, 2010.

[4] N. Sukted, P. Tuitemwong, L. E. Erickson, T. Luangtongkum, N. Chokesajjawatee, and K. Tuitemwong, "Reducing risk of campylobacteriosis from poultry: a mini review," International Journal of Food Processing Technology, vol. 4, no. 2, pp. 41-52, 2017.

[5] S. Prachantasena, P. Charununtakorn, S. Muangnoicharoen et al., "Climatic factors and prevalence of Campylobacter in commercial broiler flocks in Thailand," Poultry Science, vol. 96, no. 4, pp. 980-985, 2017.

[6] L. Vanne, M. Karwoski, S. Karppinen, and A. M. Sjöberg, "HACCP-based food quality control and rapid detection methods for microorganisms," Food Control, vol. 7, no. 6, pp. 263-276, 1996.

[7] F. Ramírez-Castillo, A. Loera-Muro, M. Jacques et al., "Waterborne pathogens: detection methods and challenges," Pathogens, vol. 4, no. 2, pp. 307-334, 2015.

[8] S. Santra, H. Yang, P. H. Holloway, J. T. Stanley, and R. A. Mericle, "Synthesis of water-dispersible fluorescent, radioopaque, and paramagnetic CdS:Mn/ZnS quantum dots: a multifunctional probe for bioimaging," Journal of the American Chemical Society, vol. 127, no. 6, pp. 1656-1657, 2005.

[9] X. Hun and Z. Zhang, "Preparation of a novel fluorescence nanosensor based on calcein-doped silica nanoparticles, and its application to the determination of calcium in blood serum," Microchimica Acta, vol. 159, no. 3-4, pp. 255-261, 2007.

[10] X. Zhao, L. R. Hilliard, S. J. Mechery et al., "A rapid bioassay for single bacterial cell quantitation using bioconjugated nanoparticles," Proceedings of the National Academy of Sciences of the United States of America, vol. 101, no. 42, pp. 1502715032, 2004.

[11] D. Qin, X. He, K. Wang, X. J. Zhao, W. Tan, and J. Chen, "Fluorescent nanoparticle-based indirect immunofluorescence microscopy for detection of Mycobacterium tuberculosis," BioMed Research International, vol. 2007, Article ID 89364, 9 pages, 2007.

[12] P. Koedrith, T. Thasiphu, K. Tuitemwong, R. Boonprasert, and P. Tuitemwong, "Recent advances in potential nanoparticles and nanotechnology for sensing food-borne pathogens and 
their toxins in foods and crops: current technologies and limitations," Sensors and Materials, vol. 26, no. 10, pp. 711-736, 2014.

[13] P. Koedrith, T. Thasiphu, J. I. Weon, R. Boonprasert, K. Tuitemwong, and P. Tuitemwong, "Recent trends in rapid environmental monitoring of pathogens and toxicants: potential of nanoparticle-based biosensor and applications," The Scientific World Journal, vol. 2015, Article ID 510982, 12 pages, 2015.

[14] N. Thepwiwatjit, A. Thattiyaphong, P. Limsuwan, K. Tuitemwong, and P. Tuitemwong, "Antibody-conjugated Rubpy dye-doped silica nanoparticles as signal amplification for microscopic detection of Vibrio cholerae O1," Journal of Nanomaterials, vol. 2013, Article ID 274805, 7 pages, 2013.

[15] N. Thepwiwatjit, A. Thattiyaphong, P. Limsuwan, K. Tuitemwong, and P. Tuitemwong, "Rubpy dye-doped silica nanoparticles as signal reporter in a dot fluorescence immunoassay strip," Journal of Nanomaterials, vol. 2014, Article ID 851905, 6 pages, 2014.

[16] N. Songvorawit, P. Tuitemwong, K. Tuchinda, and K. Tuitemwong, "Fluorescent dye-doped silica nanoparticles with polyclonal antibodies for the rapid detection of Salmonella spp.," Chiang Mai University Journal of Natural Sciences, vol. 12, no. 1, pp. 25-33, 2013.

[17] W. Tansub, K. Tuitemwong, P. Limsuwan, S. Theparoonrat, and P. Tuitemwong, "Synthesis of antibodies-conjugated fluorescent dye-doped silica nanoparticles for a rapid single step detection of Campylobacter jejuni in live poultry," Journal of Nanomaterials, vol. 2012, Article ID 865186, 7 pages, 2012.

[18] P. Tuitemwong, N. Songvorawit, and K. Tuitemwong, "Facile and sensitive epifluorescent silica nanoparticles for the rapid screening of EHEC," Journal of Nanomaterials, vol. 2013, Article ID 706354, 8 pages, 2013.

[19] ISO 16140:2003, Microbiology of Food and Animal Feeding Stuffs - Protocol for the Validation of Alternative Methods, International Organization for Standardization, Geneva, Switzerland, 2003.

[20] ISO 10272:2006, Microbiology of Food and Feeding Stuffs. Horizontal Method for the Identification and Isolation of Campylobacter spp., International Organization for Standardization, Geneva, Switzerland, 2006.

[21] D. Linton, R. J. Owen, and J. Stanley, "Rapid identification by PCR of the genus Campylobacter and of five Campylobacter species enteropathogenic for man and animals," Research in Microbiology, vol. 147, no. 9, pp. 707-718, 1996.

[22] G. D. Inglis and L. D. Kalischuk, "Use of PCR for direct detection of Campylobacter species in bovine feces," Applied and Environmental Microbiology, vol. 69, no. 6, pp. 3435-3447, 2003.

[23] G. Wang, C. G. Clark, T. M. Taylor et al., "Colony multiplex PCR assay for identification and differentiation of Campylobacter jejuni, C. coli, C. lari, C. upsaliensis, and C. fetus subsp. fetus," Journal of Clinical Microbiology, vol. 40, no. 12, pp. 4744-4747, 2002.

[24] Q. Sun, G. Zhao, and W. Dou, "An optical and rapid sandwich immunoassay method for detection of Salmonella pullorum and Salmonella gallinarum based on immune blue silica nanoparticles and magnetic nanoparticles," Sensors and Actuators B: Chemical, vol. 226, pp. 69-75, 2016.

[25] S. Gunasekaran, E. Sailatha, S. Seshadri, and S. Kumaresan, "FTIR, FT Raman spectra and molecular structural confirmation of isoniazid," International Journal of Pure and Applied Physics, vol. 47, no. 1, 2009.

[26] I. Hochel, D. Slavíčková, D. Viochna, J. Škvor, and I. Steinhauserová, "Detection of Campylobacter species in foods by indirect competitive ELISA using hen and rabbit antibodies," Food and Agricultural Immunology, vol. 18, no. 3-4, pp. 151-167, 2007.

[27] A. D. Sails, F. J. Bolton, A. J. Fox, D. R. A. Wareing, and D. L. A. Greenway, "Detection of Campylobacter jejuni and Campylobacter coli in environmental waters by PCR enzymelinked immunosorbent assay," Applied and Environmental Microbiology, vol. 68, no. 3, pp. 1319-1324, 2002.

[28] S. A. Frank, Immunology and Evolution of Infectious Disease, Princeton University Press, Oxford, UK, 2002.

[29] J. Cohen, "A coefficient of agreement for nominal scales," Educational and Psychological Measurement, vol. 20, no. 1, pp. 37-46, 1960.

[30] J. R. Landis and G. G. Koch, "The measurement of observer agreement for categorical data," Biometrics, vol. 33, no. 1, pp. 159-174, 1977.

[31] W. Vencia, C. Nogarol, D. M. Bianchi et al., "Validation according to ISO 16140: 2003 of a commercial real-time PCR-based method for detecting Campylobacter jejuni, C. coli, and C. lari in foods," International Journal of Food Microbiology, vol. 177, pp. 78-80, 2014.

[32] Y. Hong, M. E. Berrang, T. Liu et al., "Rapid detection of Campylobacter coli, C. jejuni, and Salmonella enterica on poultry carcasses by using PCR-enzyme-linked immunosorbent assay," Applied and Environmental Microbiology, vol. 69, no. 6, pp. 3492-3499, 2003.

[33] M. Lund, S. Nordentoft, K. Pedersen, and M. Madsen, "Detection of Campylobacter spp. in chicken fecal samples by realtime PCR," Journal of Clinical Microbiology, vol. 42, no. 11, pp. 5125-5132, 2004. 


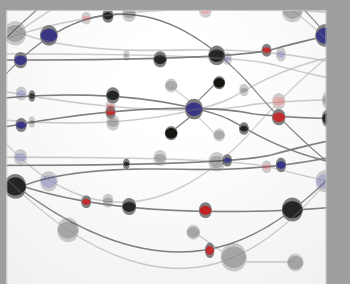

The Scientific World Journal
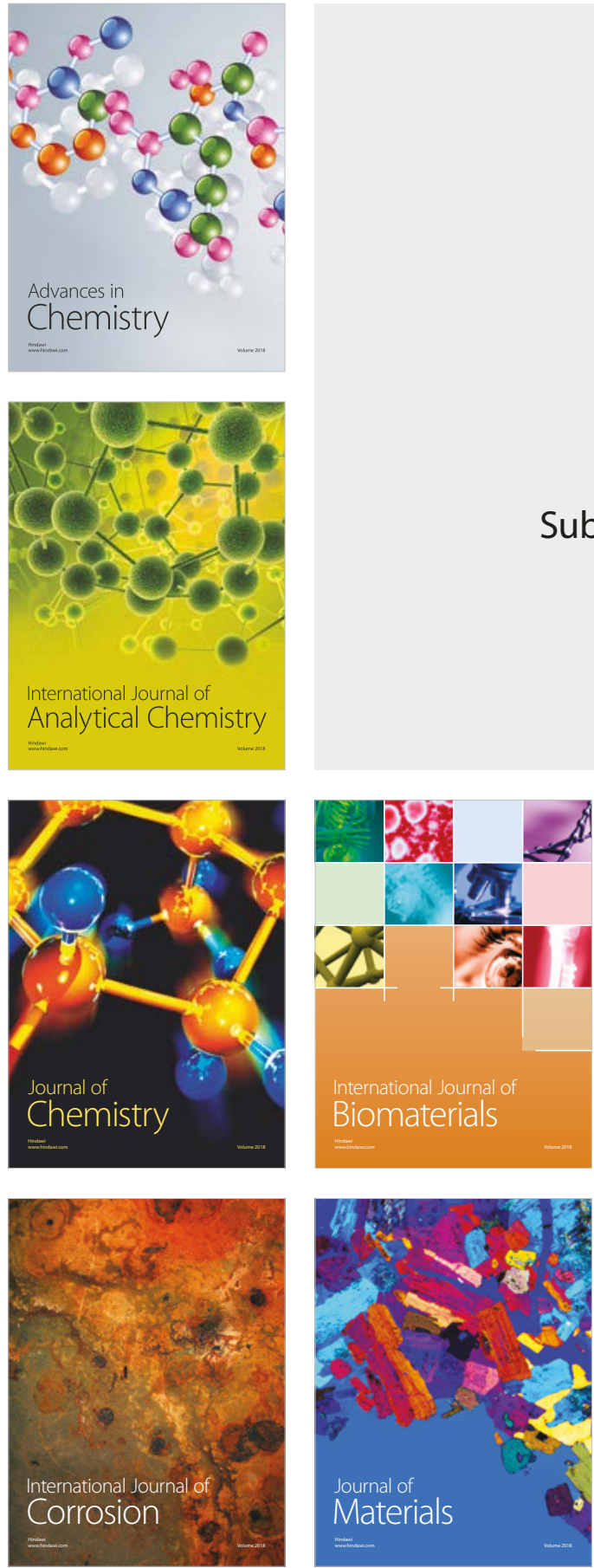

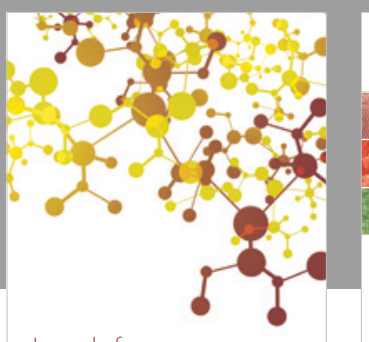

Journal of

Applied Chemistry
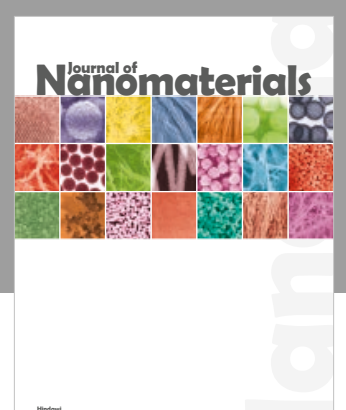

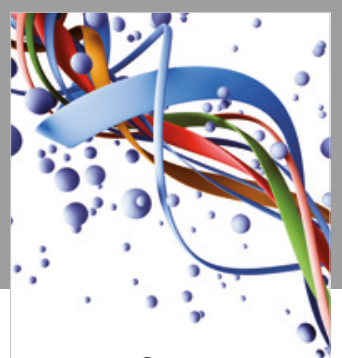

Scientifica

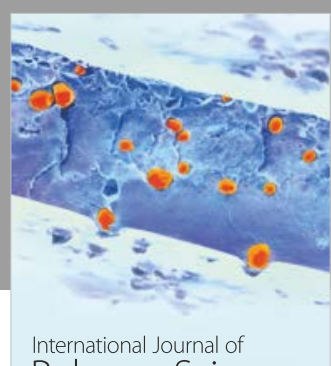

Polymer Science

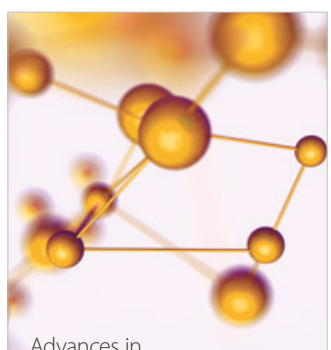

Physical Chemistry
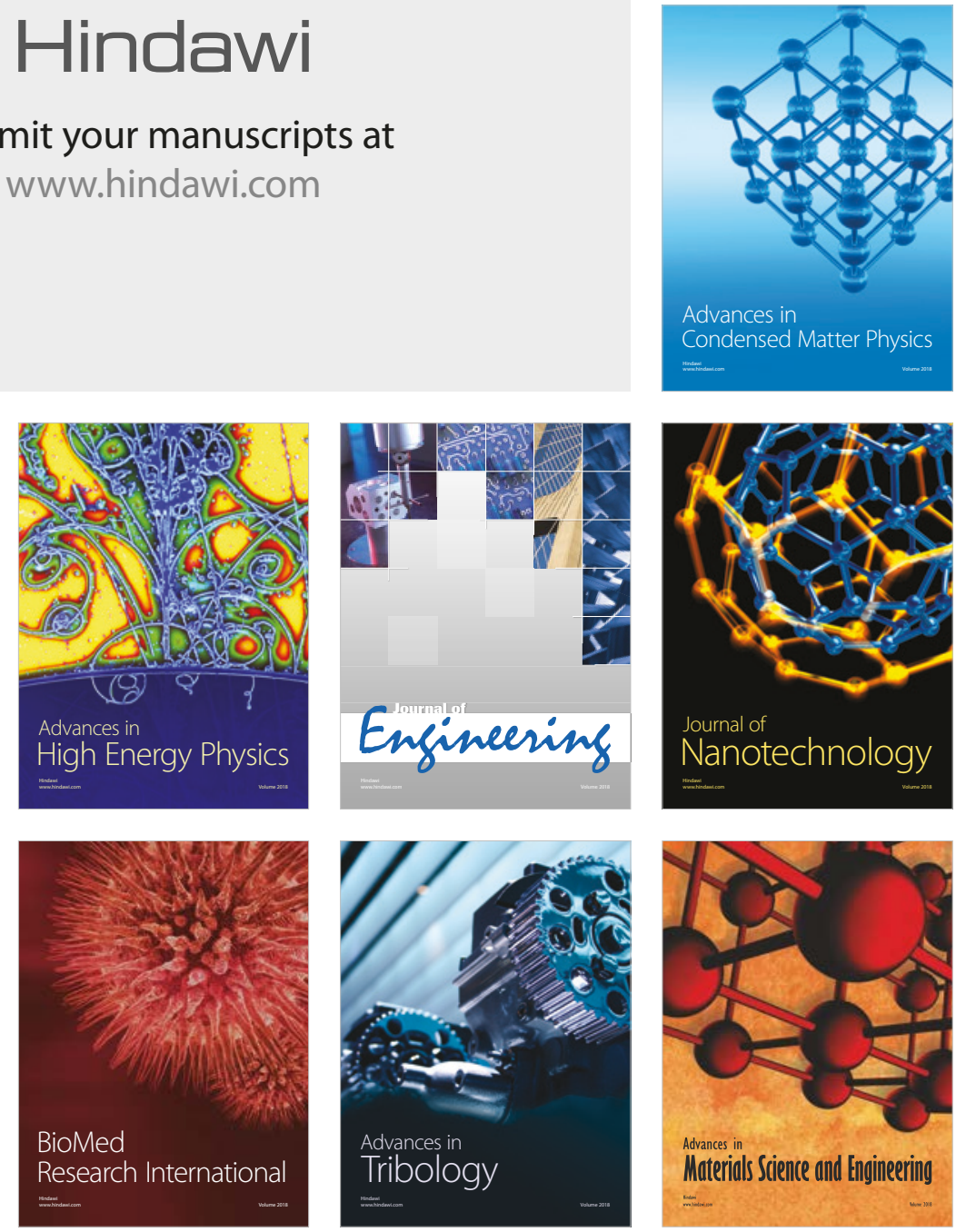